\title{
Klaus Oschema, Cristina Andenna, Gert Melville, Jörg Peltzer (dir.), Die Performanz der Mächtigen
}

Pierre Monnet

\section{OpenEdition}

Journals

Édition électronique

URL : http://journals.openedition.org/ifha/9449

DOI : $10.4000 /$ ifha. 9449

ISSN : 2198-8943

Éditeur

IFRA - Institut franco-allemand (sciences historiques et sociales)

Référence électronique

Pierre Monnet, « Klaus Oschema, Cristina Andenna, Gert Melville, Jörg Peltzer (dir.), Die Performanz der Mächtigen », Revue de I'IFHA [En ligne], Date de recension, mis en ligne le 23 août 2018, consulté le 24 septembre 2020. URL : http://journals.openedition.org/ifha/9449; DOI : https://doi.org/10.4000/ifha. 9449

Ce document a été généré automatiquement le 24 septembre 2020.

(C)IFHA 


\section{Klaus Oschema, Cristina Andenna, Gert Melville, Jörg Peltzer (dir.), Die Performanz der Mächtigen}

Pierre Monnet

\section{RÉFÉRENCE}

Klaus Oschema, Cristina Andenna, Gert Melville, Jörg Peltzer (dir.), Die Performanz der Mächtigen. Rangordnung und Idoneität in höfischen Gesellschaften des Mittelalters, Ostfildern: Jan Thorbecke Verlag (RANK 5), 2015, 240 p., $39 €$ 
Le concept sociologique et anthropologique de performance a pris depuis plusieurs années place dans la boîte à outils des historiens, plus spécialement des médiévistes qui, avec le recours et le concours des normes, des rites, des symboles, ont appris à multiplier ainsi les angles d'attaque et les interprétations d'une documentation souvent lacunaire, biaisée et avant tout elle-même " performée » par des attentes, des gestes, des opérations, des actes etc. qui certes y affleurent mais ne sont pas dévoilés de la même manière que dans nos sociétés modernes et contemporaines.

Dès l'introduction à ce recueil d'études issues de deux rencontres organisées à la Villa Vigoni puis à Dresde en 2011 et 2013, Klaus Oschema retrace l'archéologie de

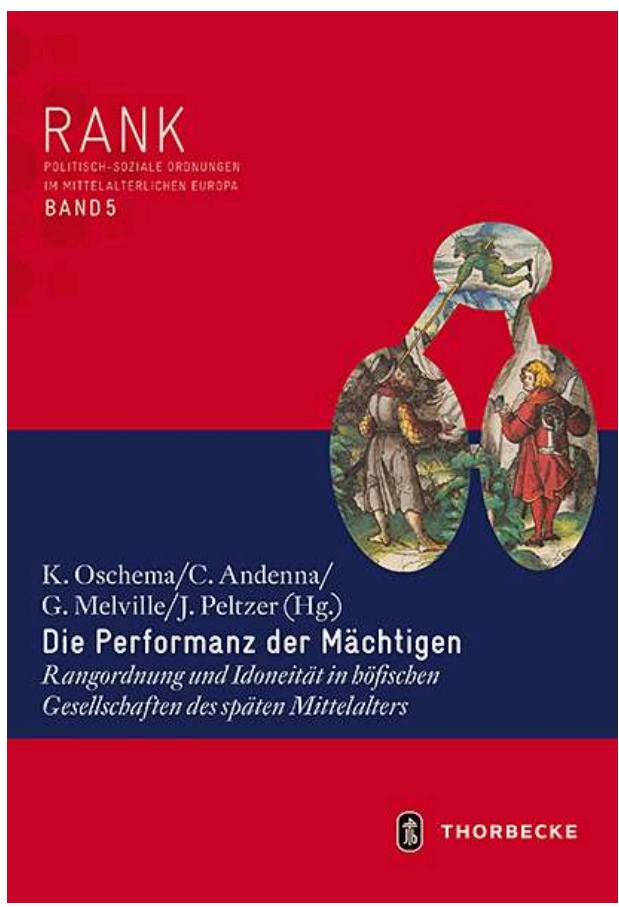
l'emploi du terme et de son instrumentation dans la médiévistique européenne, avec un point de départ situé dans les années 1990 jusqu'à une saturation dangereuse de son usage aujourd'hui. Il en va en effet du performative turn comme des autres tournants (linguistique, visuel, rituel, scripturaire, spatial etc.), passant d'un exercice initialement salutaire et pionnier à un concept-valise qui, à force de trop étreindre, finit par tout et mal embrasser: la diplomatie, le parler, les émotions, la guerre... bref tous les actes réalisés en société et pourvus d'un sens. Pour baliser et réhabiliter le champ performatif, les concepteurs des rencontres et du volume ont d'abord voulu limiter le périmètre d'observation à la cour et aux institutions de pouvoir au sein desquelles l'autorité et la souveraineté ont besoin de se montrer et de se légitimer. À cette première restriction s'est ajoutée une limitation chronologique: une fin du Moyen Âge traversée par les phénomènes d'étatisation, de réforme et de refonte du contrat entre la royauté et les sujets. Enfin, un troisième bornage s'est employé à concentrer le questionnaire non pas sur " ce qui » se produit mais sur le fait que "cela" se produise et en même temps sous «quelle forme " (non pas was, mais dass et wie).

On peut évidemment discuter du gain réellement obtenu par ce resserrement: on trouve réunies en effet dans le volume des analyses touchant aux marques de légitimité du pouvoir royal, au rang et à la préséance de cour, à la rhétorique des puissants, au tournoi, aux couronnements et jusqu'au légendaire impérial, bref à toute une série hétéroclite de phénomènes que l'on rencontre depuis longtemps balayés par le performative turn. L'introduction, et à sa suite la conclusion de Gert Melville, en devinent bien la difficulté, et prennent soin de préciser que le resserrement visé tend à focaliser le regard sur les performances comme signes d'une culture ou, mieux, d'un système culturel (ce que fut bien la cour), accompagnées de processus de communication (effet de propagande et de persuasion, mises par écrit, représentations visuelles et symboliques, opérations discursives, jeux de la mémoire) et de mise en scène, incorporant une série de schèmes et d'actes « en présence » posant la question 
de leur prévisibilité, de leur légitimité (et de celle de leurs acteurs), bref de leur lisibilité sociale et, avec la distance des siècles, de leur historicité.

Le fil rouge retenu pour tenter de mettre en lumière ces lignes directrices et de relier les diverses contributions tient dans la notion d'idonéité. Le terme présente au moins l'avantage d'appartenir au vocabulaire des médiévaux, sur la base du latin idoneus désignant tout acte, toute personne ou tout objet "convenable ", "compétent", " conforme », «apte ", "adéquat »... Il permet ensuite de restreindre la lecture de la 'performance' d'une situation à ce qui, dans les sphères du pouvoir curial et souverain de la fin du Moyen Âge, contribue à établir l'adéquation d'un discours, d'une décision, d'une transaction entre son auteur/acteur politique et les destinataires ou les attentes et théories du temps qui en ont motivé et structuré la logique. Ainsi peut-il en aller d'un couronnement, d'un tournoi, de la conclusion d'une paix, du comportement d'un prince ou d'un roi envers ses sujets ou ses pairs, entre approbation, critique et contrôle de conformité.

Une dimension toutefois, celle de la temporalité de cette 'performance', est nécessairement comprise dans une telle démarche. Elle aurait pu, nous semble-t-il, se retrouver encore davantage placée au cœur de l'attention et n'a été abordée que par le biais des dispositifs de légitimation déployés notamment au XIII ${ }^{\mathrm{e}}$ siècle par les rois et les cours de l'Empire, de France, de Hongrie et de Sicile (article de Cristina Andenna) ou par celui de l'usage postérieur (singulièrement au XIII ${ }^{e}$ siècle dans l'article de Mathias Standke, un germaniste soit dit en passant...) des images et des légendes de Charlemagne à des fins de légitimation du pouvoir royal entre imitation et distance. L'efficacité et la lisibilité d'une performance sociale dans la société de pouvoir tardomédiévale, tout comme dans d'autres contextes, engagent en effet un certain rapport entre passé, présent et avenir à l'aune duquel la performativité d'un acte, d'un discours, d'un rituel est plus ou moins conforme aux attentes et aux interprétations «idoines " des acteurs d'un temps précis, puis cesse à un moment donné de l'être et ne devient plus que souvenir mort ou désuet installant un décalage qui ruine la signification même d'une performance, la rend caduque, voire déplacée, en un mot « inadéquate ». Manière de dire que l'idonéité en histoire est inséparable de l'historicité de sa définition et de son agir.

\section{INDEX}

Thèmes : Histoire des États et des pouvoirs, Historiographie/Méthodologie

Index chronologique : Moyen Âge

\section{AUTEURS}

PIERRE MONNET

EHESS (Paris) et IFRA-SHS (Frankfurt am Main) 